\title{
The Influence Of Organizational And Social Support On Turnover Intention In Collectivist Contexts
}

Patipan Lobburi, Ph.D., Kokkrabrue, Maung, Samutsakorn, Thailand

\begin{abstract}
A model investigating both antecedents of perceived social support and organizational support in predicting turnover intention process of Thai workers was developed and tested via structural equation modeling. Based on previous research, the arguments between the effects of perceived workplace and non-workplace social support on turnover intention were raised in an individualistic cultural context. Turnover research still does not clearly explain how organizational support influences attitudinal outcomes (job satisfaction) and work related outcomes (organizational commitment and turnover intention). Consequently, this study attempts to test the effect of workplace and non-workplace social support on turnover intention in a collectivistic culture in which people have a strong relationship with family and friends and investigates the influence of perceived organizational support on turnover intention in a Thai context. Six hundred and sixty six workers completed attitude surveys. The results indicated that perceived social support from supervisors, coworkers, and family and friends, and perceived organizational support policy, such as fairness rewards, participation in decision-making and growth opportunities, were positively related to job satisfaction. In addition, job satisfaction mediated the relationship among perceived social and organizational support, organizational commitment, and leaving intention of processing-canned-and-frozen-seafood workers in Thailand.
\end{abstract}

Keywords: Organizational Support; Workplace Social Support; Non-Workplace Social Support; Job Satisfaction; Organizational Commitment; Turnover Intention

\section{INTRODUCTION}

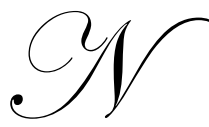

owadays, many workers all over the world habitually intend to leave their jobs and seek new job opportunities because they believe a new job will provide more benefits, job security, and experiences, or they could avoid conflict in their current job. Unfortunately, Thai factories are also facing these problems. A high turnover rate in the country, especially in food sectors, makes the factories confront many dilemmas, such as shortage of skillful employees, loss of productivity, loss of business to competitors, and high costs of recruitment and training. Therefore, employee retention in the food sector has become a significant topic and challenge for Thai researchers to find out the ways to retain Thai workers. Thailand is called the "kitchen of the world" because of the export value of its food goods. Understanding how to reduce labor shortages in the food industry is likely to benefit export values and the gross domestic product (GDP) of the country.

For more than five decades, organizational and turnover researchers (March \& Simon, 1958; Mobley, 1982; Price, 1977; Price \& Mueller, 1986) have paid attention to the broad factors both inside (e.g., benefits, job stress, work environment, etc.) and outside the organization (e.g., alternative jobs, kinship responsibilities, etc.) that have affected an individual's leaving decision. Likewise, perceived social support and organizational support theories are accepted as affecting attitudinal outcomes (job satisfaction) and work-related outcomes (organizational commitment and turnover intentions) because the objective of social support is for individuals to help each other in the social construction of networks and to reduce uncertainty, anxiety, and stress when individuals are faced with problems and crises, and perceived organizational support conveys the meaning of caring and concern for employee wellbeing. 
To date, the majority of turnover research has been conducted in individualist cultures and has been primarily focused on either perceived organizational support theory (e.g., fairness rewards, participation in decisionmaking and growth opportunities) or workplace social support (e.g., supervisor and coworker) with little attention being paid to non-workplace social support (e.g., family and friends). However, the way of being Thai pointed that non-workplace interpersonal relationships potentially contributed to the studies of the attitudinal and work-related outcomes. Therefore, the purpose of this study is to explore both perceived organizational support and social support (workplace and non-workplace social support) and their relationship with turnover processes in a Thai context. Recommendations for further developing of the theoretical model will be explored.

\section{WORKPLACE AND NON-WORKPLACE SOCIAL SUPPORT AND TURNOVER INTENTION PROCESS}

Generally, workers confront problems, ambiguities, and conflicting role demands, which induce role strain in the workplace while job satisfaction is diminished by ambiguity and conflicts. Hence, most turnover research has affirmed that role stress encourages dissatisfaction and resignation (Fisher \& Gitelson, 1983; Hom \& Griffeth, 1995; Jackson \& Schuler, 1985; Lyons, 1968). In general, global workers do not encounter stress by themselves but within the networks to which they belong. Most workers share experiences and regularly help people in their social network cope with difficult times by providing instrumental and emotional support. Evidence indicates that significantly perceived social support leads to job satisfaction by providing workers with a sense of wellbeing (Infante, Anderson, Martin, Herington, \& Kim, 1993; Infante \& Gorden, 1991; Vischer, 2007).

Based on a relatively large number of empirical studies, the researcher found that perceived workplace social support from supervisors and coworkers have been found to be a working condition that improves job satisfaction and organizational commitment that in turn reduces turnover intention (House, 1981; Karasek \& Theorall, 1990; Mor Barak, Nissly, \& Levin, 2001; Um \& Harison, 1998). Generally speaking, workers who received care from their social network in the workplace experienced more satisfaction and commitment within their organizations and wanted to stay longer than those who felt lonely. On the one hand, several turnover studies (e.g., Rycraft, 1994; Vinokur-Kaplan, 1991) focusing on the effect of workplace social support (e.g., supervisors and coworkers) and non-workplace social support (e.g., family and friends) on turnover intention have been conducted in individualistic cultural contexts with few studies (e.g., Brough \& Frame, 2004; Lee, 2004), however, investigating these effects in collectivistic cultural contexts. The literature indicated that only coworker (Remsberg, Armacost, \& Bennett, 1999) and supervisor support could reduce turnover intention (Bernatovicz, 1997) indirectly through job satisfaction and organizational commitment.

In spite of this, the researcher argued that perceived social support is a process of social interaction and communication within a social network that relies on a different kind of relationship, such as social relationship, family relationship, and workplace relationship. Accordingly, in societies in which people have strong social ties with family and friends, as in collectivist culture, non-workplace related factors (e.g., family and friends, kinship responsibilities, etc.) may also affect job satisfaction and work related outcomes of employees (e.g., organizational commitment and turnover intention) (Mobley, Griffeth, Hand, \& Meglino, 1979; Steers \& Mowday, 1981). Consequently, the researcher posits that perceived support from supervisors, coworkers, and family and friends is positively related to job satisfaction. In addition, the researcher expects that job satisfaction will be positively related to organizational commitment, and in turn, organizational commitment will be negatively related to turnover intention (see in Figure 1).

\section{PERCEIVED ORGANIZATIONAL SUPPORT AND TURNOVER INTENTION PROCESS}

The perceived organizational support (POS) theory explains how positive treatments from different organizational agents, such as offering participation in decision-making, establishing fairness rewards, and providing growth opportunities (Eisenberg, Aselage, Sucharski, \& Jones, 2004), will impact job satisfaction that in turn will affect organizational commitment and turnover intention. Evidently, perceived organization support directly affects perceptions of the relationship between individuals and organizations. Likewise, March and Simon (1958) suggested that the individual decision to leave or remain in an organization depends on the balance between the benefits that the organization offers and an individual's expectations of the organization. Therefore, workers in the organization who perceive that the organization values their contributions and is concerned with their wellbeing might have low leaving intentions (Eisenberger, Huntington, Huchison, \& Sowa, 1986). 
There are many studies of the impact of perceived organizational support on turnover. For example, Huselid (1995) assumed that investments in practices (e.g., promotion within organization, labor-management participation) could help the organization retain workers. Likewise, Shaw, Delery, Jenkins, and Gupta (1998) found fair pay, good benefits, and high job autonomy would reduce an organization's turnover rates. Similarly, Arthur (1994) found that organizations that allowed workers to get involved in managerial decisions, formal participation, and socializing activities could reduce worker turnover rates. However, Griffeth, Hom, and Gaertner (2000) reviewed the causes of turnover from the prior empirical studies that were conducted in the twentieth century and found a small negative effect of justice distribution, promotion chances, and participation on turnover. Surprisingly, a small negative effect size of these predictors remained mostly unchanged when compared with the latest metaanalysis (Hom \& Griffeth, 1995). Therefore, they concluded that perceived organizational support is not directly associated with turnover intentions, but the relationship of organizational support to turnover rates was moderated by job satisfaction and organizational commitment. Consequently, the researcher posits that perceived fairness rewards, participation in decision-making, and growth opportunities are positively related to job satisfaction (see in Figure 1).

\section{JOB SATISFACTION, ORGANIZATIONAL COMMITMENT, TURNOVER INTENTION AND TURNOVER}

Turnover intention is a worker's act of thinking about quitting after they have experienced, dissatisfaction, uncomfortable, and a worker's decrease of commitment to the organization etc. For instance, Mobley (1977) suggested that although turnover intention manipulates the impetuous behavior to quit, there are main factors that prompt employees to think about leaving, such as organizational commitment and job satisfaction. Based on empirical turnover research, this study conceptualizes a general cognition of withdrawal that subsumes specific intention to leave. In addition, this study posits turnover intentions as the outcome measure because turnover intention has been found to be one of the best predictors of actual turnover (Griffeth, Hom, \& Gaertner, 2000).

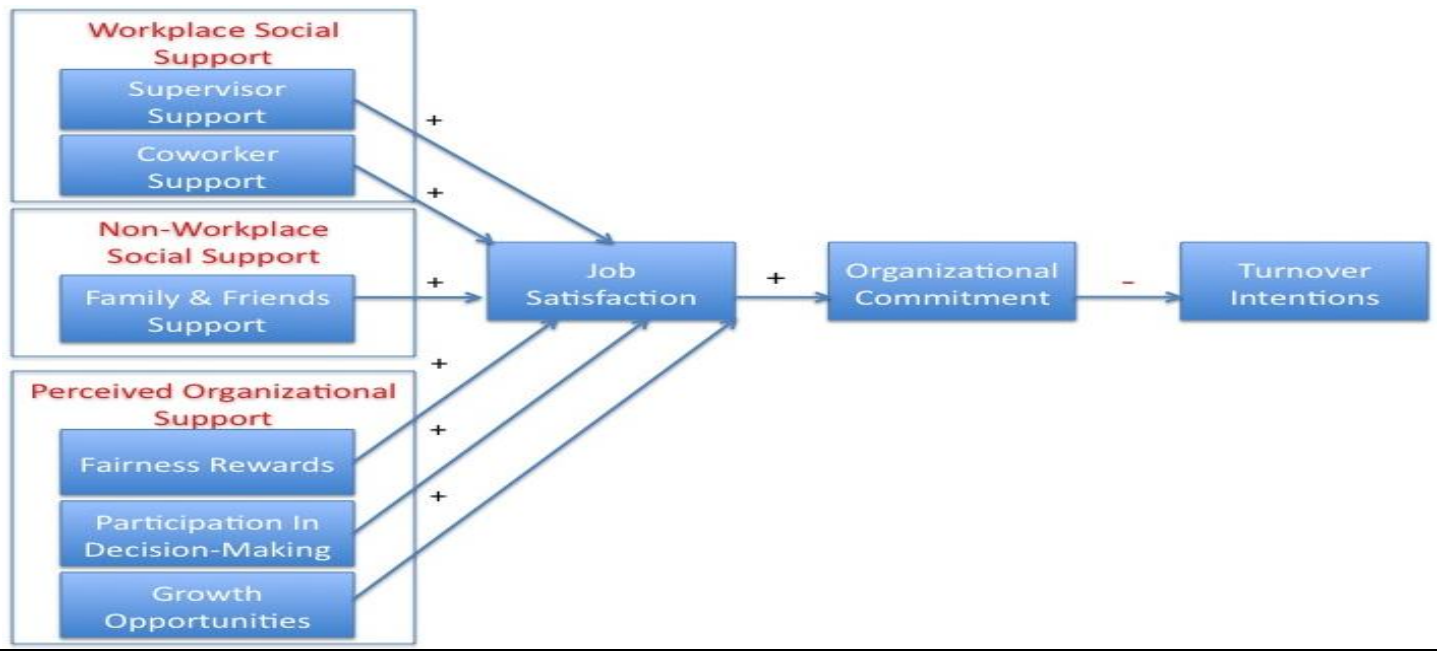

Figure 1: Theoretical Model

\section{SUMMARY}

Based on the previous fuzzy studies above and cultural differences (individualist versus collectivist), the researcher hypothesizes that in Thai organizations, non-workplace (family and friends) social support will be positively related to job satisfaction similarly organizational support (fairness rewards, participation in decisionmaking and growth opportunities) and workplace social support (supervisor and coworker). Furthermore, these supports will be positively related to organizational commitment, and in turn, organizational commitment will be negatively related to turnover intention. Furthermore, the researcher expects that this study contributes to a fundamental understanding of how intention to leave the organization is constructed through interpersonal networks both inside and outside organizations and organizational supportive policy. Last, but not least, the results of this study can have practical implications for planning strategic designs to retain workers in collectivist societies. 


\section{METHODOLOGY}

\section{Sample and Procedure}

The model was tested using data collected by a questionnaire survey. A letter accompanied the survey emphasizing the confidentiality of responses and assuring respondents that only members of the research team would have access to the responses offered by the respondents. Seven hundred and fifty workers who are working in five processing-canned-and-frozen-seafood factories in Bangkok and its suburbs were randomly selected to answer to the questionnaire. Finally, 723 questionnaires were returned, 672 questionnaires were deemed useable; the remaining questionnaires were unusable due to incompleteness and other reasons that compromised their utility. In addition, 6 cases were considered to be outliers so that the demographic data from 666 participants is discussed in this chapter.

\section{Measurement}

All measurements are self-reported and assessed using a 5-point Likert-type response scale with anchors ranging from $1=$ strongly disagree to $5=$ strongly agree. The instruments are used to operationalize the constructs that have been adopted from previous researches, which are shown below.

Leaving Intention. Lee (2004) adapted a three-item scale from Peter and Jackofsky (1979) and a one-item scale from Mobley, Horner, and Hollingsworth (1978) to measure leaving intention variables. The items required a period of less than six months before exercising leaving. A sample item is, "I intend to leave my job in the next 6 months."

Job Satisfaction. In 1935, Hoppock developed an instrument to measure job satisfaction. His four-item scale of job satisfaction has been measured with a generalized, global standard. However, Lee (2004) argued that one item of the four-item scale related to leaving intention. Therefore, Lee removed that one item to avoid contamination. A sample item is "I enjoy working in my job most of the time."

Organizational Commitment. Bozeman and Perrewé (2001) suggested using a nine-item scale of the organizational commitment questionnaire (OCQ) that removed the withdrawal-related items to assess employees' general psychological attachment to the organization because there were no substantive differences in the results achieved between the two versions (Allen, Shore, \& Griffeth, 2003). A sample item is, "I am willing to put in a great deal of effort beyond that normally expected in order to help this organization be successful."

Social Support. Social support is measured using the instrument developed by Caplan, Copp, French, Harison, and Pinneau (1975) and modified by Lee (2004). The social support scale includes three subgroups (e.g., supervisor, coworker, and family and friends support) that contain a twelve-item scale on the instrument. A sample item is, "When things get tough at work, I can always rely on my coworker [replaced by supervisor/ family and friends] to help me solve the problem."

Organizational Support. A fifteen-item scale measured organizational support. The new scale was adapted from three existing scales: participation in decision-making scale (Steel \& Mento, 1987), fairness of reward/recognition scale, and growth opportunities scale (Price \& Mueller, 1986). These three factors were integral to the measurement of the organizational support scale. Sample items include, "Within my work-group the people most affected by decisions frequently participate in making the decisions"; "I feel that my current job responsibilities are fair"; and "There is a good chance to get ahead" respectively.

\section{Analytical Procedure}

One-way ANOVAs (F-Test) were used to assess whether the means of five factories statistically differ from each other then identical analyses were performed. Descriptive statistical analyses, such as means and standard deviations, were employed to make clear the characteristics of each variable. Following this procedure, the internal consistency (Cronbach's Alpha) for all scales used to measure the ratio of true score variance and observed score variance were run. A confirmatory factor analysis (CFA) was used to assess the distinctiveness of measures with Amos 16.0 graphics for Windows to evaluate the fit of the measurement model. Several statistics (e.g., standardized 
root-mean-square residual, goodness-of-fit index, Tucker-Lewis index, etc.) were used to evaluate model fit because sample size often affects the goodness-of-fit-chi-square. Following the recommendation of Hu and Bentler (1999) to interpret multiple fit indices, the researcher supplemented several fit statistics, such as $\chi^{2}$ test, root-mean-square error of approximation (RMSEA), and standardized root-mean-square residual (SRMR) with the goodness-of-fit index (GFI), the comparative fit index (CFI), and the Tucker-Lewis index (TLI). Therefore, to demonstrate adequate fit, the model should have a nonsignificant Chi-square or meet the following targets for incremental tests: GFI, CFI, TLI (.90 or greater), RMSEA (.06 or less), and SRMR (.09 or less). Finally, after assessing the fit of confirmatory factor models, the researcher evaluates the complete structural model represented in Figure 1.

\section{RESULTS}

Among the 750 questionnaires distributed to five factories, $96 \%$ were returned, approximately $91 \%$ were usable. After data screening, there were 666 questionnaires contained in further analysis. The one-way ANOVAs were conducted to determine mean difference among nine variables of interest. The thorough inspection of the mean difference comparison revealed that there were no mean differences from the five factories across all of the variables. Given these results, it was concluded that all factories should be included to assess the overall structural equation. Approximately, three-fourths of respondents (75\%) are female. Approximately, half of the respondents (52\%) had spent more than five years working in their factory, the majority of respondents $(45 \%)$ were between 30 and 39 years old". Mostly, $48 \%$ of the respondents had completed a college or higher degree.

\section{Descriptive Statistics, Correlations, and Cronbach's Alphas}

Table 1: Descriptive Statistics

\begin{tabular}{|c|c|c|c|c|c|c|c|c|c|c|c|}
\hline \multirow[b]{2}{*}{ Constructs } & \multicolumn{5}{|c|}{ Cronbach's } & \multirow[b]{2}{*}{3} & \multirow[b]{2}{*}{4} & \multirow[b]{2}{*}{5} & \multirow[b]{2}{*}{6} & \multirow[b]{2}{*}{7} & \multirow[b]{2}{*}{8} \\
\hline & Mean & S.D. & Alphas & 1 & 2 & & & & & & \\
\hline Supervisor Support & 13.42 & 3.39 & 0.89 & - & & & & & & & \\
\hline $\begin{array}{l}\text { Coworker Support } \\
\text { Family \& Friends }\end{array}$ & 13.83 & 3.48 & 0.90 & $.23 * *$ & & & & & & & \\
\hline $\begin{array}{l}\text { Support } \\
\text { Participation in }\end{array}$ & 13.82 & 3.30 & 0.88 & $.09 *$ & $.09 *$ & & & & & & \\
\hline $\begin{array}{l}\text { Decision Making } \\
\text { Growth }\end{array}$ & 18.06 & 3.55 & 0.90 & $.34 * *$ & $.24 * *$ & $.16^{* *}$ & & & & & \\
\hline Opportunities & 18.35 & 3.5 & 0.87 & $.36 * *$ & $.28 * *$ & $.14 * *$ & $.71 * *$ & & & & \\
\hline $\begin{array}{l}\text { Fairness Rewards } \\
\text { Organizational }\end{array}$ & 16.97 & 3.67 & 0.87 & $.29 * *$ & $.17 * *$ & $.14 * *$ & $.60 * *$ & $.61 * *$ & & & \\
\hline Commitment & 29.8 & 8.47 & 0.95 & $.44 * *$ & $.36 * *$ & $.22 * *$ & $.53 * *$ & $.53 * *$ & $.49 * *$ & & \\
\hline Job Satisfaction & 8.74 & 3.07 & 0.85 & $.41 * *$ & $.39 * *$ & $.19 * *$ & $.45^{* *}$ & $.45^{* *}$ & $.44 * *$ & $.74 * *$ & \\
\hline & & & & - & - & - & - & - & - & - & - \\
\hline Leaving Intention & 9.33 & 4.05 & 0.95 & $.51 * *$ & $.44 * *$ & $.21 * *$ & $.56^{* *}$ & $.58 * *$ & $.51 * *$ & $.73 * *$ & $.65 * *$ \\
\hline
\end{tabular}

The descriptive statistics, such as means, standard deviations, correlations, and Cronbach's alphas among the study's variables, are shown in Table 1. The antecedents of social support (supervisor, coworker, and family and friends) were all significantly correlated with one another but not so highly (Hayduk, 1987) as to suggest that multicollinearity disappeared to be a problem. Each of social support antecedents was also significantly related to organizational commitment, job satisfaction, and leaving intention. Organizational commitment and job satisfaction were the most strongly correlated variables. All of the study variables were significant and negatively related to turnover intention. Particularly, supervisor support was more strongly related than the other sources of social support, and growth opportunities variable was more strongly related than the other sources of organizational support. Furthermore, organizational commitment was most strongly related than other study variables. Table 1 shows that all constructs have moderately high reliabilities, which are .85 and above.

\section{Confirmatory Factor Analysis (CFA)}

A confirmatory factor analysis (CFA) was performed to assess the distinctiveness of the measures. Each measurement of the study was specified as one-dimensional with appropriate items loading on their respective 
factors. The results of the CFA displayed in Table 2 indicated an acceptable fitting measurement model. All $\chi 2$ tests were not statistically significant and all fit indices were within the recommended RMSEA and SRMR ranges $<.06$ and .09 respectively, while CFI, NFI, and GFI > .90 (Clara, Brain, Murray, Linda, \& Laine, 2003; Bollen, 1989). As the overall goodness of fit is promising, the results of confirmatory factor models are encouraged to be further tested against the magnitudes and the significance of the path of structural coefficients in the theoretical model.

Table 2: Summary of Fit Indices of Confirmatory Factor Analysis (CFA)

\begin{tabular}{|l|c|c|c|c|c|c|c|c|}
\hline Model & $\boldsymbol{\chi 2}$ & $\mathbf{d f}$ & $\mathbf{P}$-value & CFI & NFI & TLI & RMSEA & SRMR \\
\hline Social Support & 63.458 & 51 & 0.113 & 0.997 & 0.986 & 0.996 & 0.019 & 0.024 \\
\hline Organizational Support & 89.330 & 87 & 0.411 & 1.000 & 0.985 & 1.000 & 0.006 & 0.017 \\
\hline Job Satisfaction & 1.892 & 1 & 0.169 & 0.999 & 0.998 & 0.997 & 0.037 & 0.008 \\
\hline Organizational Commitment & 30.552 & 27 & 0.290 & 0.999 & 0.994 & 0.999 & 0.014 & 0.012 \\
\hline Turnover Intention & 4.497 & 2 & 0.106 & 0.999 & 0.998 & 0.997 & 0.043 & 0.005 \\
\hline
\end{tabular}

\section{Structural Equation Modeling (SEM)}

As indicated by statistics reported in Table 2, all of the confirmatory factor models were satisfied because they had adequate fit with the data. Therefore, the assessment of the complete structural equation model represented in Figure 1 was performed. Amos 16.0 was used to assess the multiple indices of overall model fit and path coefficient estimates of the theoretical model. To complete Figure 1, although the $\chi^{2}$ statistic was significant $\left(\chi^{2}\right.$ $(846 d f)=1459.99 \mathrm{p}<.05)$, this statistic is sensitive to sample size and model complexity. As such, $\chi 2 / d f$ was 1.73 , and the fit indices were quite good (RMSEA $=.033$; SRMR $=.126$; $\mathrm{CFI}=.970 ; \mathrm{NFI}=.932$; $\mathrm{TLI}=.968)$ and indicated an acceptable fitting model. All of the path estimates were significant and went in the expected direction.

The antecedents of the social and organizational support policies, such as supervisor support (.28), coworker support (.29), family and friends support (.11), fairness rewards (.26), participation in decision-making (.16), and growth opportunities (.11) were positively related to job satisfaction. Furthermore, job satisfaction (.83) was positively related to organizational commitment. Organizational commitment (-.75) was negatively related to turnover intention. The completely standardized solution can be found in Figure 2. Finally, the results illustrate that the six sources of social and organizational support explained $47 \%$ of the variances in job satisfaction, which in turn explained $70 \%$ of the variance in organizational commitment. Additionally, for the entire theoretical model, the multiple correlation was $.75\left(\mathrm{R}^{2}=.56\right)$, which suggests that $56 \%$ of the variability in this model was for the relationships that the researcher hypothesized. When comparing the five antecedents of social and organizational support, the variable of coworker support had the greatest total direct causal effect on job satisfaction with a path coefficient of 29 .

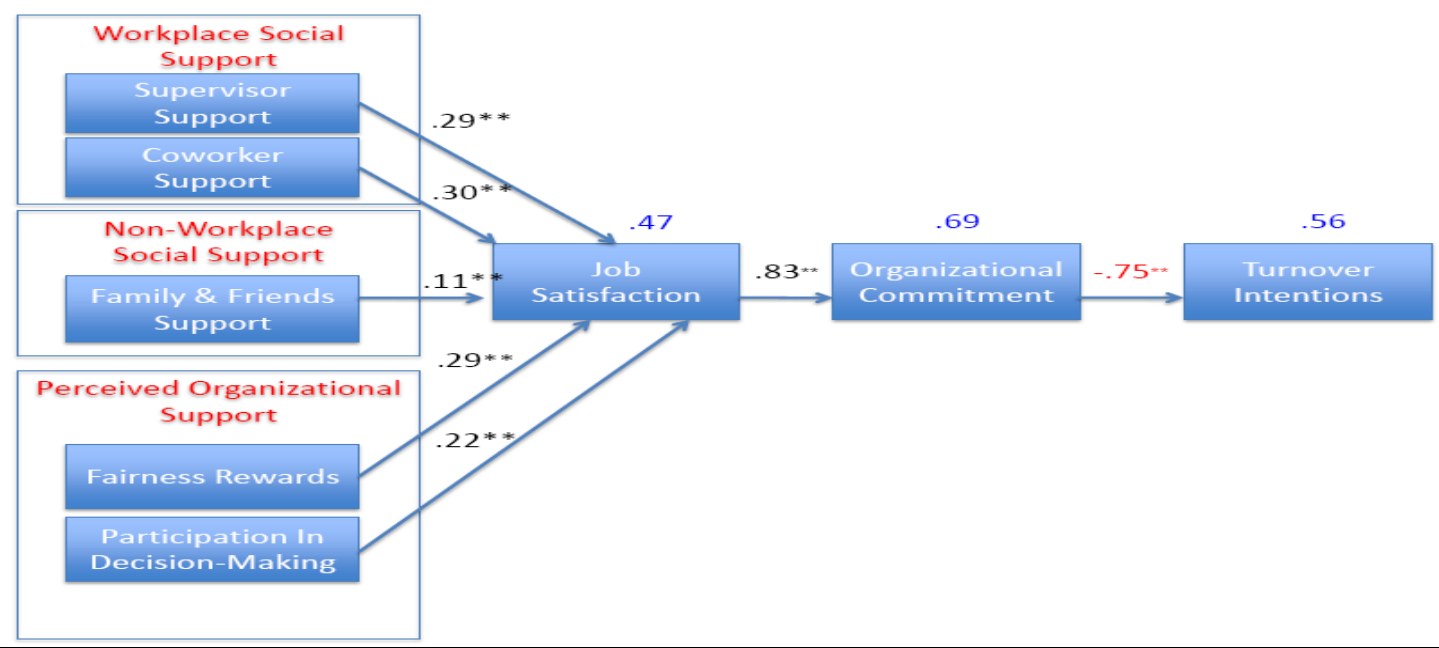

Figure 2. Theoretical model results

Noted: $*<.05$ and $* *<.01$ 


\section{DISCUSSION}

Analyses of the structural equation model indicated that the theoretical model was a good fit of the empirical data. The model explained a large proportion of the variance in three endogenous variables: job satisfaction, organizational commitment, and turnover intention. Furthermore, all predicted paths were significant in the theoretical model as indicated in the path diagram in Figure 2. Workplace social support (i.e., supervisor and coworker support) and non-workplace social support (i.e., family and friends) and fairness rewards, participation in decision-making and growth opportunities directly and significantly affected job satisfaction. However, nonworkplace social support and growth opportunities illustrated the lowest effect on job satisfaction. Additionally, job satisfaction mediated the relationship between various kind of supports and work-related outcomes, such as organizational commitment and turnover intention.

The findings of this study add important information to the theoretical understanding of how strong relationships with family and friends in a collectivist culture affect attitudinal (job satisfaction) and work related outcomes (organizational commitment and turnover intention). First, unlike recent studies of social support and turnover intention (see Brough \& Frame 2004; Shimazu, Shimazu, \& Odahara, 2004), the results suggest that in a collectivist cultural context, not only does workplace social support (supervisor and coworker support) influence the satisfaction, commitment, and turnover intention of workers but also non-workplace social support (family and friends support). This finding is consistent with collectivist culture that describes societies in which people are integrated into strong, cohesive in-groups and families (Hofstede, 1991). Therefore, the findings assert that the influences of non-workplace social support (family and friends) on turnover intention from the study conducted in collectivist culture are different from individualistic cultures. Employees in individualistic societies may fail to notice that support from their family and friends influence their turnover intention because persons in individualistic societies are expected to look after themselves and their immediate family but rarely anyone else. Also, they value personal time, freedom, challenge, and the right to private, personal opinions (Hofstede, 1991). Thus, the evidence of this study suggests that subjective culture can influence job satisfaction, organizational commitment, and turnover intention, and "the psychological features of a culture, including assumptions, values, and patterns of thinking" (Hoft, 1996, p.43) are important factors to which turnover research and managers have to attend when they investigate turnover processes.

Second, the results of the study indicate that workplace social support (supervisors and coworkers) is the stronger total causal effect on satisfaction than non-workplace social support (family and friends) and other organizational support policy. The finding of workplace social support is consistent with cultural practices that privilege hierarchical systems and power distance, which further emphasize the role of interpersonal relationships between supervisors and subordinates in Thai organizations. Similarly, Niratpattanasai (2004) suggested that Thai workers are socialized to respect elders and leaders and generally rely on strong relationships with friends. Therefore, hierarchical systems, power distance, and strong social ties often affect Thai workers in terms of avoiding conflict with their supervisors and coworkers. Thus, cooperation with coworkers and supervisors in organizations is a significant factor that can increase job satisfaction, organizational commitment, and intention to stay.

Finally, the findings of the study assume that the effects of social support and organizational policies on organizational commitment and leaving intention were mediated by job satisfaction. Likewise, Stumpf and Hartman (1984) and Tett and Meyer (1993) suggested that social support may be a more distal determinant of turnover that affects turnover as a critical antecedent to job satisfaction and organizational commitment. Consequently, it is reasonable to point out that turnover intention can be reduced by social support and organizational policies through two mediators-job satisfaction and organizational commitment.

\section{IMPLICATIONS FOR RESEARCH AND PRACTICE}

In addition to its theoretical contributions, the study also has practical implications for human research development (HRD). Social support plays an important role in leaving intention of Thai workers. Therefore, personnel practitioners need to recognize that they can use social support, especially workplace social support, such as supervisor and coworker support, to manage job satisfaction, organizational commitment, and turnover intention. It may be easier and more realistic to use social support to retain workers because human resource managers can 
learn to cultivate social support, such as activities and events in organizations, that help them to build a supportive network in the workplace. For instance, organizations should establish informal forums where workers can talk about work practice (e.g., lunchtime meetings) and also arrange formal scheduled support sessions with coworkers or managers and supervisors or both (Pidd et al., 2004). Scheduled sessions are one strategy to ensure that workers have the opportunity to access support, guidance, and direction—especially from supervisors (Maslach, 1982).

Furthermore, organizations should invest in training (e.g., leadership and communication) for their supervisors because the study found that supervisor support had the greatest effect on job satisfaction. Note that, although this study reported that non-workplace support (family and friends) had a small effect on job satisfaction, it had the smallest indirect effect on organizational commitment and turnover intention so that non-workplace support might be a supplement to a retention plan. For instance, human resource managers can increase job satisfaction and intention to stay of their workers by managing working hours and creating events in which workers can participate with their family to reduce work-family conflict and role stressor. Additionally, the findings of the study suggest that organizations should improve job satisfaction if human resource practitioners and managers want to increase organizational commitment and retain their workers by conducting job satisfaction surveys or satisfactory assessment at least once every year so that the organizations can be aware of employee attitudes toward work-related outcomes.

Even though the findings of this study provide potentially fruitful information for those interested in turnover, especially in collectivistic cultural contexts, future research should address questions and limitations apparent in these findings. First, in this study, leaving intention was tested as the outcome variable instead of the actual departure because time constraints. Therefore, a longitudinal design would be appropriate for future studies. Second, the theoretical model in this study was tested only in canned food industry; therefore, generalization is limited to industrial context. To address this problem, future studies should test using multi-sample analysis that involves analyzing data from various industries (e.g., electrical appliance and textile industries) and various professionals (e.g., labor workers, white collar workers, and intellectuals) simultaneously. Third, the theoretical model posits that several of the relationships among model constructs are mediated. Thus, there may be plausible alternative models that include more direct paths that still need to be investigated. Finally, the quantitative data cannot reveal the rich experiences of turnover intention and the various expressed forms of job satisfaction and organizational commitment. To address this problem, future research could collect qualitative data to describe the content of job satisfaction, organizational commitment, and turnover intention.

\section{AUTHOR INFORMATION}

Patipan Lobburi is a senior executive in marketing field. He obtained his doctorate from Bangkok University, in cooperation with Ohio University. His research interests include organizational communication, interpersonal communication, and health communication. Contact: 38/6 Moo 4, Kokkrabrue, Maung, Samutsakorn, Thailand, 74000. E-mail: p1893608@ohio.edu

\section{REFERENCES}

1. Alexander, J., Lichtenstein, R., Oh, H. J., \& Ullman, E. (1998). A causal model of turnover among nursing personnel in long-term psychiatric settings. Research in Nursing and Health, 21, 415- 427.

2. Allen, D. G., Shore, L. M., \& Griffeth, R. W. (2003). The role of perceived organizational support and supportive human resource practices in the turnover process. Journal of Management, 29(1), 99-118.

3. Angle, H. L., \& Perry, J. L. (1981). An empirical assessment of organizational commitment and organizational effectiveness. Administrative Science Quarterly, 26(1), 1-14.

4. Bernatovicz, F. (1997). Retention of child welfare caseworkers: A report. Portland, ME: National Center for Organizational Improvement.

5. $\quad$ Bollen, K. A. (1989). Structural Equations with Latent Variables. New York: Wiley.

6. Bozeman, D.P., \& Perrewé P.L. (2001). The effect of item content overlap on Organizational Commitment Questionnaire-turnover cognition relationships. Journal of Applied Psychology, 86, 161-173. 
7. Brough, P., \& Frame, R. (2004). Predicting police job satisfaction, work well-being and turnover intentions: The role of social support and police organizational variables. New Zealand Journal of Psychology, 33, 8-18.

8. Caplan, R. D., Copp, S., French, J. R. P., Harison, R. U., \& Pinneau, S. R. (1975). Job demand and worker health. (U.S. Department of Health, Education and Welfare Publication 75-160) Washington, DC: The Institute for Social Research, U.S. Government Printing Office.

9. Chou, R. J., \& Robert, S. A. (2008). Workplace support, role overload, and job satisfaction of direct care workers in assisted living. The Journal of Health and Social Behavior, 49, 208-222.

10. Cicero-Reese, B., \& Black, P. (1998). Research findings suggest why child welfare workers stay on job. Partnerships for Child Welfare Newsletter, 5(5), 8-9.

11. Clara, I. P., Brain, J. C., Murray, W. E., Linda, T. M., \& Laine, J. T. (2003). Confirmatory factor analysis of the multidimensional scale of perceived social support in clinically distressed and student samples. Journal of Personality Assessment, 81(13), 265-270.

12. Dickinson, N. S., \& Perry, R. E. (2002). Factors influencing the retention of specially educated public child welfare workers. Journal of Health \& Social Policy, 15(3/4), 89-103.

13. Feeley, T. H., Hwang, J., \& Barnett, G. A. (2008). Predicting employee turnover from friendship networks. Journal of Applied Communication Research, 36, 56-73.

14. Fisher, C. D., \& Gitelson, R. (1983). A meta-analysis of the correlates of role conflict and ambiguity. Journal of Applied Psychology, 68(2), 320-333.

15. Fisher, C. D. (1985). Social support and adjustment to work: A longitudinal study. Journal of Management, 11(3), 39-53.

16. Gow, J. S., Clark, A. W., \& Dossett, G. S. (1974). A path analysis of variables influencing labour turnover. Human Relations, 27(7), 703-719.

17. Granovetter, M. (1986). The microstructure of school desegregation. In J. Prager, D. Longshore, \& M. Seeman (Eds.), School desegregation research: New directions in situational analysis (pp. 81-110). New York: Plenum Press.

18. Griffeth, R. W., Hom, P. W., \& Gaertner, S. (2000). A meta-analysis of antecedents and correlates of employee turnover: Update, moderator tests, and research implications for the next millennium. Journal of Management, 26(3), 463-488.

19. Hackett, R. D., Lapierre, L. M., \& Hausdorf, P. A. (2001). Understanding the links between work commitment constructs. Journal of Vocational Behavior, 58(3), 392-413.

20. Hayduk, L. A. (1987). Structural Equation Modeling with LISREL: Essentials and Advances. Baltimore: Johns Hopkins University Press.

21. Hofstede, G. H. (1991). Culture and organizations: Software of the mind. London: McGraw Hill.

22. Hoft, N. (1996). Developing a Cultural Model. In: Del Galdo, E., Nielson, J. (eds.): International User Interfaces. John Wiley and Sons, New York (1996).

23. Holtz, G. A. (1982). Nurses' aides in nursing homes: Why are they satisfied? Journal of Gerontological Nursing, 8(5), 265-271.

24. Hom, P. W., \& Griffeth, R. W. (1995). Employee turnover. Cincinnati, OH: South-Western College Publishing Company.

25. Hoppock, R. (1935). Job satisfaction. New York: Arno Press.

26. House, J. S. (1981). Work stress and social support. Reading, MA: Addison-Wesley.

27. Hu, L., \& Bentler, P.M. (1999). Cutoff criteria for fit indices in covariance structure analysis: Conventional criteria versus new alternatives. Structural Equation Modeling, 6, 1-55.

28. Infante, D. A., \& Gorden, W. I. (1991). How employees see the boss: Test of an argumentative and affirming model of supervisors' communicative behavior. Western Journal of Speech Communication, 55, 294-304.

29. Infante, D. A., Anderson, C. M., Martin, M. M., Herington, A. D., \& Kim, J (1993). Subordinates' satisfaction and perceptions of superiors' compliance-gaining tactics, argumentativeness, verbal aggressiveness, and style. Management Communication Quarterly, 6(3), 307-326.

30. Jackson, S. E., \& Schuler, R. S. (1985). A meta-analysis and conceptual critique of research on role ambiguity and role conflict in work settings. Organizational Behavior and Human Decision Processes, 36 , 16-78. 
31. Kalleberg, A. L., \& Mastekaasa, A. (2001). Satisfied movers, committed stayers: The impact of job mobility on work attitudes in Norway. Work and Occupations, 28(2), 183-209.

32. Karasek, R., \& Theorell, T. (1990). Healthy work: Stress, productivity, and the reconstruction of working life. New York: Basic Books.

33. Kreitner, R., \& Kinicki, A. (2006). Organizational behavior (7th ed.). New York: McGraw-Hill.

34. Lee, K., Carswell, J. J., \& Allen, N. J. (2000). A meta-analytic review of occupational commitment: Relations with person- and work-related variables. Journal of Applied Psychology, 85(5), 799-811.

35. Lee, P. C. B. (2004). Social support and leaving intention among computer professionals. Information and Management, 41, 323-334.

36. Lum, L., Kervin, J., Clark, K., Reid, F., \& Sirola, W. (1998). Explaining nursing turnover intent: job satisfaction, pay satisfaction, or organizational commitment? Journal of Organizational Behavior, 19, $305-$ 320 .

37. Lyons, T. F. (1968). Nursing attitudes and turnover. Ames, IA: Iowa State University, Industrial relations Center.

38. March. J. G., \& Simon, H. A. (1958). Organizations. New York: Wiley Press.

39. Maslach, C. (1982). Burnout - the cost of caring. Englewood Cliffs, NJ: Prentice-Hall.

40. Mathieu, J. E., \& Zajac, D. M. (1990). A review and meta-analysis of the antecedents, correlates, and consequences of organizational commitment; Psychological Bulletin, 108(2), 171-194.

41. Meyer, J. P., \& Allen, N. J. (1997). Commitment in the workplace: Theory, research and application. CA: Sage Publications.

42. Meyer J. P., Stanley, D. J., Herscovitch, L., \& Topolnytsky, L. (2002). Affective, continuance, and normative commitment to the organization: A meta-analysis of antecedents, correlates and consequences. Journal of Vocational Behavior, 61, 20-52.

43. Mobley, W. H. (1977). Intermediate linkages in the relationship between job satisfaction and employee turnover. Journal of Applied Psychology, 62(2), 237-240.

44. Mobley, W. H. (1982). Employee turnover: Causes, consequences, and control. Reading, MA: AddisonWesley.

45. Mobley, W. H., Griffeth, W., Hand, H., \& Meglino, B. (1979). Review and conceptual analysis of the employee turnover process. Psychological Bulletin, 86(3), 493-522.

46. Mobley, W. H., Horner, S. O., \& Hollingsworth, A. T. (1978). An evaluation of precursors of hospital employee turnover. Journal of Applied Psychology, 63(4), 408-414.

47. Mor Barak, M. E., Nissly, J. A., \& Levin, A. (2001). Antecedents to retention and turnover among child welfare, social work, and other human service employees: What can we learn from past research? A review and metanalysis. Social Science Review, 75(4), 625-661.

48. Mossholder, K. W., Setton, R. P., \& Henagan, S. C. (2005). A relational perspective on turnover: Examining structural, attitudinal, and behavioral predictors. Academy of Management Journal, 48(4), 607618.

49. Mowday, R. T., Porter, L. W., \& Steers, R. M. (1982). Employee-organization linkages, the psychology of commitment, absenteeism and turnover. New York: Academic Press.

50. Munn, E. K., Barber, C. E., \& Fritz, J. J. (1996). Factors affecting the professional well-being of child life specialists. Children's Health Care, 25(2), 71-91.

51. Niratpattanasai, K. (2004). Bridging the gap: Managing the cross-cultural workplace in Thailand. Bangkok: Asia Books

52. Nissley. J. A., Mor Barak, M. E., \& Levin, A. (2005) Stress, social support, and workers' intention to leave their jobs in public child welfare. Administration in Social Work, 29(1), 79-100.

53. O'Reilly III, C. A., Caldwell, D. F., \& Barnett, W. P. (1989). Work group demography, social integration, and turnover. Administrative Science Quarterly, 34, 21-37.

54. Peters, L. H., \& Jackofsky, E. F. (1979). Predicting turnover: A field test of the Mobley model. In: Proceedings of the 21st annual meeting of the Southwest Academy of Management, Houston, TX.

55. Pidd, K., Freeman, T., Skinner, N., Addy, D., Shoobridge, J., \& Roche, A.M. (2004). From training to work practice change: An examination of factors influencing training transfer in the alcohol and other drugs field. Canberra: Australian Government Department of Health and Ageing.

56. Porter, L. W., Steers, R. M., Mowday, R. T., \& Boulian, P. V. (1974) Organizational commitment, job satisfaction, and turnover among psychiatric technicians. Journal of Applied Psychology, 59(5), 603-609. 
57. Price, J. L. (1977). The study of turnover. Ames: Iowa State University Press.

58. Price, J. L. \& Mueller, C. W. (1981). A causal model of turnover for nurses. Academy of Management Journal, 24(3), 543-565.

59. Price, J. L. \& Mueller, C. W. (1986). Absenteeism and turnover of hospital employees. Greenwich, CT: JAI Press.

60. Rappoport, R. \& Rappoport, R. N. (1976). Dual career families re-examined: New integrations of work \& family. New York: Harper and Row.

61. Remsberg, R. E., Armacost, K. A., \& Bennett, R. G. (1999). Improving nursing assistant turnover and stability rates in a long-term care facility. Geriatric Nursing, 20(4), 203-208.

62. Rhoades, L., \& Eisenberger, R. (2002). Perceived organizational support: A review of the literature. Journal of Applied Psychology, 87(4), 698-714.

63. Rycraft, J. (1994). The party isn't over: The agency role in the retention of public child welfare caseworkers. Social Work, 39(1), 75-80.

64. Schaefer, J. A., \& Moos, R. H. (1996). Effects of work stressors and work climate on long-term care staffs' job morale and functioning. Research in Nursing and Health, 19, 63-73.

65. Shimazu, A., Shimazu, M., \& Odahara, T. (2004). Job control and social support as coping resources in job satisfaction. Psychological Reports, 94(2), 449-456.

66. Spector, P. E. (1985). Higher-order need strength as a moderator of the job scope-employee outcome relationship: A meta-analysis. Journal of Occupational Psychology, 58, 119-127.

67. Steers. R. M., \& Mowday, R. T. (1981). Employee turnover and the post decision accommodation process. In B. M. Shaw \& L. L. Cummings (Eds.), Research in Organization Behavior: Vol. 3 (pp. 235-281).

Greenwich, CT: JAI Press.

68. Stumpf, S. A., \& Hartman, K. (1984). Individual exploration to organizational commitment and withdrawal. Academy of Management Journal, 27(2), 308-329.

69. Tett, R. P., \& Meyer, J. P. (1993). Job satisfaction, organizational commitment, turnover intention, and turnover: path analyses based on meta-analytic findings. Personnel Psychology, 46(2), 259-293.

70. Um, M-Y., \& Harison, D. F. (1998). Role stressors, burnout, mediators, and job satisfaction: A stressstrain-outcome model and an empirical test. Social Work Research, 22(2), 100- 115.

71. Vinokur-Kaplan, D. (1991). Job satisfaction among social workers in public and voluntary child welfare agencies. Child Welfare, 70(1), 81-91.

72. Vischer, J. C. (2007). The effects of the physical environment on job performance: Towards a theoretical model of workplace stress. Stress and Health, 23, 175-184.

73. Yeatts, D. E., \& Seward, R. R. (2000). Reducing turnover and improving health care in nursing homes: The potential effects of self-managed work teams. The Gerontologist, 40(3), 358-363. 
NOTES 